\title{
Intersecting Identities of Women in Engineering
}

\section{Dr. Ruby Mendenhall, University of Illinois at Urbana-Champaign}

Ruby Mendenhall is an Associate Professor at the University of Illinois, Urbana-Champaign. She holds joint faculty appointments in Sociology, African American Studies, Urban and Regional Planning, Social Work and Gender and Women's Studies.. She is currently a faculty member at the Carl R. Woese Institute for Genomic Biology and a faculty affiliate at the Institute for Computing in the Humanities, Arts and Social Sciences, Women and Gender in Global Perspective, and Gender and the Cline Center for Democracy. She is an Assistant Dean at the Carle Illinois College of Medicine. She is the recipient of the Richard and Margaret Romano Professorial Scholar for outstanding achievements in research and leadership on campus. She is also a Grand Challenge Learning Teaching Fellow in the Health Track. Mendenhall's research focuses on racial microaggressions in higher education. She examines how living in racially segregated neighborhoods with high levels of violence affects Black mothers' mental and physical health using qualitative, quantitative and genomic analysis. She uses big data to recover Black women's lost history using topic modeling and data visualization to examine over 800,000 documents from 1740 to 2014. Mendenhall also does research on the Earned Income Tax Credit (EITC).

\section{Dr. Kelly J. Cross, University of Illinois, Urbana-Champaign}

Dr. Cross completed her doctoral program in the Engineering Education department at Virginia Tech in 2015 and worked as a post-doctoral researcher with the Illinois Foundry for Innovation in Engineering Education at the University of Illinois at Urbana-Champaign. At UIUC she has collaborated with multiple teams of engineering faculty on implementing and assessing instructional innovation. Dr. Cross is currently a Research Scientist in the Department of Bioengineering working to redesign the curriculum through the NSF funded Revolutionizing Engineering Departments (RED) grant. She is a member of the ASEE Leadership Virtual Community of Practice that organizes and facilitates Safe Zone Training workshops. Dr. Cross has conducted multiple workshops on managing personal bias in STEM, both online and in-person. Dr. Cross' scholarship investigates student teams in engineering, faculty communities of practice, and the intersectionality of multiple identity dimensions. Her research interests include diversity and inclusion in STEM, intersectionality, teamwork and communication skills, assessment, and identity construction. Her teaching philosophy focuses on student centered approaches such as problem-based learning and culturally relevant pedagogy. Dr. Cross' complimentary professional activities promote inclusive excellence through collaboration.

\section{Dr. Jennifer R. Amos, University of Illinois, Urbana-Champaign}

Dr Amos joined the Bioengineering Department at the University of Illinois in 2009 and is currently a Teaching Associate Professor in Bioengineering and an Adjunct Associate Professor in Educational Psychology. She received her B.S. in Chemical Engineering at Texas Tech and Ph.D. in Chemical Engineering from University of South Carolina. She completed a Fulbright Program at Ecole Centrale de Lille in France to benchmark and help create a new hybrid masters program combining medicine and engineering and also has led multiple curricular initiative in Bioengineering and the College of Engineering on several NSF funded projects.

\section{Dr. Kathryn B.H. Clancy, University of Illinois, Urbana-Champaign}

Dr. Kathryn Clancy is an Associate Professor of Anthropology at the University of Illinois. Her research interests are in human reproductive ecology, particularly ovarian and endometrial function, as well as in issues of intersectionality and inclusion in science. Dr. Clancy and her collaborators have examined relationships between inflammation and ovarian function in rural agricultural and urban sedentary environments, and explored ways of non-invasively studying the endometrium in rural contexts. Recently she and her colleagues have empirically demonstrated the continued problem of sexual harassment and assault in the field sciences, including a link between these experiences and the career trajectories of female scientists. She continues to perform research on issues of inclusion, identity, and diversity in science 
through collaborations with GAMES, the Committee for the Status of Women in Astronomy, and other organizations.

\section{Prof. Princess Imoukhuede, University of Illinois at Urbana Champaign}

Dr. Princess Imoukhuede is an Assistant Professor of Bioengineering at the University of Illinois at Urbana Champaign. She received her S.B. in Chemical Engineering with a minor in Biomedical Engineering from the Massachusetts Institute of Technology, and she received her Ph.D. in Bioengineering from the California Institute of Technology. Prior to joining Illinois, Dr. Imoukhuede completed a postdoctoral fellowship in Biomedical Engineering at Johns Hopkins University School of Medicine. Her research interests are at the interface of Systems Biology and Angiogenesis with applications to Breast Cancer and Cardiovascular Disease.

\section{Jennifer G. Cromley, University of Illinois at Urbana-Champaign}




\section{The Intersecting Identities of Women in Engineering}

Introduction

The inequities that plague our society are mirrored in higher education and arguably exacerbated in STEM fields. Giving a voice to marginalized groups and understanding the double bind of race and gender on university campuses is critical, especially after the Charlottesville, VA protests, white supremacist efforts to bring in Nazi sympathizing speakers, and rampant sexual misconduct towards undergraduates documented across the country. The result of this discourse and uncivil behavior, as well as more subtle beliefs about white superiority, are interpersonal and institutional barriers that lead to limited participation of women, particularly women of color, and thus the loss of their presence and expertise within the field of engineering and STEM, more broadly.

The "chilly climate" is often cited as an explanation for the loss of women from STEM. The "chilly climate" is defined as women in the male dominated STEM fields feeling unwelcome 123 or people of color experiencing a diminished sense of belonging within engineering profession ${ }^{4}$ ${ }^{5}{ }^{6}$ based upon daily social interactions that threaten the identity of females in STEM ${ }^{7}$, men in STEM settings who treat women in subtle sexist ways ${ }^{8}$. However, interactions that allow the "chilly climate" to persist have yet to be characterized. This lack of understanding can inhibit the professional engineering identity construction of women. Additionally, postsecondary education research typically focuses on a single identity dimension such as gender ${ }^{9}$, which ultimately excludes assessment or understanding of the lived experiences of those with multiple marginalities, such as women of color (WOC). These studies connect single identity dimensions to student outcomes and few studies clarify how the intersection of identities are situated within the social context of the engineering culture. Consequently, a need exists to examine how the engineering culture impacts multiple components of identity and the intersection of identities within women. To address this gap, our study illuminates the intersections of identity of women in engineering and how WOC perceive the double bind of race and gender within the context of their engineering education.

The data reported here are a part of a larger, sequential mixed-methods study $(\mathrm{N}=276)$ of undergraduate female engineering students at a large Midwestern research university. This project applies the framework of intersectionality with the following scales: Engineering Identity, Ethnic Identity, Womanist Identity, Microaggressions, and Depressive Symptoms. We use intersectionality to investigate the interaction between intersecting social identities and educational conditions. The Womanist Identity Attitude scale (WIAS) provides an efficient way to understand gender, racial, and intersecting identity development of WOC. We utilize the microaggressions scale, in order to develop quantitative measures of gender-racial discrimination in STEM. We also included the Patient Health Questionnaire (PHQ-9), an instrument for measuring depressive symptoms, to assess health outcomes of respondents' experiences of gender-racial microaggressions.

Our three emergent findings suggest instrument accuracy and provide insight into the identity and depression subscales. Factor analysis established a basis to refine our quantitative survey instruments, and indicated that 23 items could offer greater accuracy than the original 54 items of the WIAS instrument. Second, the majority of participants report a high level of identification 
with engineering. This result rebuffs the long-held stereotypes that females are less interested in engineering. Third, a significant portion of female respondents self-reported PHQ-9 scores in the 15-19 range, which corresponds with a "major depression, moderately severe" provisional diagnosis, the second-highest in severity in the PHQ-9 provisional diagnosis scale. Women with elevated levels of depressive symptoms were significantly more likely to also report frequent instances of microaggressions. These preliminary findings are providing never-before seen insight into the experiences of women in engineering. Our results suggest a path to accurately describe the experiences of women and WOC in engineering, while revealing options for improving inclusion efforts.

\section{Method}

A sequential mixed methods study is employed to allow us to best answer the research questions

10. The first phase is a quantitative survey followed by interviews to allow participants to further explicate their survey answers and their perceptions as a woman of color in engineering. The qualitative and quantitative data will have equal priority and will be connected through data analysis to triangulate the results. The survey was administered in the Fall semester of 2016 and the opened-ended questions were coded using qualitative analytical techniques (e.g. thematic coding). The response rate for our survey was roughly $20 \%$ of the female population within the college. The mixed methodology provides flexibility to analyze the data, provides more complete answers to research questions, and is aligned with our intersectionality framework and theoretical perspective ${ }^{111213}$. However, the focus of this paper summarizes our evaluation process of our survey instrument. The survey instrument was piloted before data collection began and we consulted intersectionality expert researchers for face validation.

\section{Theoretical Framework}

Intersectionality provides the overall framework for the study. While the concepts of intersectionality are established in social science research, the use of an intersectionality is a novel approach for STEM scholarship and it is rarely considered in STEM education studies on marginalized groups. Thus, most studies of underrepresented minorities in STEM ignore the interrelated relationship of race and gender on the lived experiences of women and men of color 14. Moreover, intersectionality approaches are necessary because the dynamics of gender plays out differently across racial groups in STEM settings when researchers acknowledge the interrelatedness of identities and take a holistic approach ${ }^{15}$. In the larger study, we intentionally focus on and highlight the intersection of race and gender or the "double bind" of WOC in STEM from an intersectionality approach. Indeed, it is the primary analysis approach, a key component to the research design, and part of the development of the research questions. The current study applies intersectionality as an analysis process with a methodology consistent with fundamental feminist principle through which intersectionality was created. Specifically, we follow an analysis process recommended by intersectionality research experts ${ }^{16}$ and situate our study in the larger conversation of intersectionality beyond the two dimension of race and gender. The dearth of intersectionality research in engineering education can mask challenges that impact women with multiple oppressed identities. In this paper, we describe the results of our factor analysis to evaluate our survey instrument to capture the intersecting identities of women in the college of engineering. The analysis is part of the first phase of this mixed methods study and our two guiding research questions (RQs) are: 
RQ1: Are the subscales selected for the Women in Engineering survey valid and reliable for the population sample?

RQ2: Are there statistically significant relationships between the Women in Engineering subscales and evidence of intersecting identities?

Table 1: Scale Abbreviations, Descriptions, Number of Items and Cronbach Alpha Values

\begin{tabular}{|c|c|c|c|}
\hline Abbreviation & Scale Description & $\begin{array}{l}\text { No. } \\
\text { Items } \\
\end{array}$ & Reliability \\
\hline ENG_IDTY & Identification with Engineering (IE) ${ }^{17}$ & 5 & 0.70 \\
\hline EI_EXP & Ethnic Identity subscale exploration ${ }^{5}$ & 3 & 0.82 \\
\hline EI_COM & Ethnic Identity subscale commitment ${ }^{5}$ & 3 & 0.75 \\
\hline WIAS_PRE & Womanist Identity Attitude Scale (WIAS) subscale PRE-encounter ${ }^{6}$ & 8 & 0.53 \\
\hline WIAS_ENC & Womanist Identity Attitude Scale (WIAS) subscale ENCounter ${ }^{6}$ & 7 & 0.51 \\
\hline WIAS_IMEM & Womanist Identity Attitude Scale (WIAS) subscale Immersion/Emersion ${ }^{6}$ & 10 & 0.79 \\
\hline WIAS_INT & Womanist Identity Attitude Scale (WIAS) subscale Internalization ${ }^{6}$ & 7 & 0.57 \\
\hline PHQ_WK & Patient Health Questionnaire 2 weeks ${ }^{8}$ & 9 & 0.90 \\
\hline RMA_SEM & Racial Microaggressions 2 Semester ${ }^{7}$ & 9 & 0.86 \\
\hline
\end{tabular}

\section{Participants}

A combination of sampling approaches were used in order to study the sample who identified as a female student currently enrolled in the college of engineering $(\mathrm{N}=267)$. In the larger population, $13 \%$ of participants self-identified as first generation and $86 \%$ indicated their socioeconomic status as middle to upper class. All participants were initially contacted by email and provided a link to the survey containing participation requirements and consent information.

Figure 1: Self-Selected Racial and Ethnic Identity Percentages

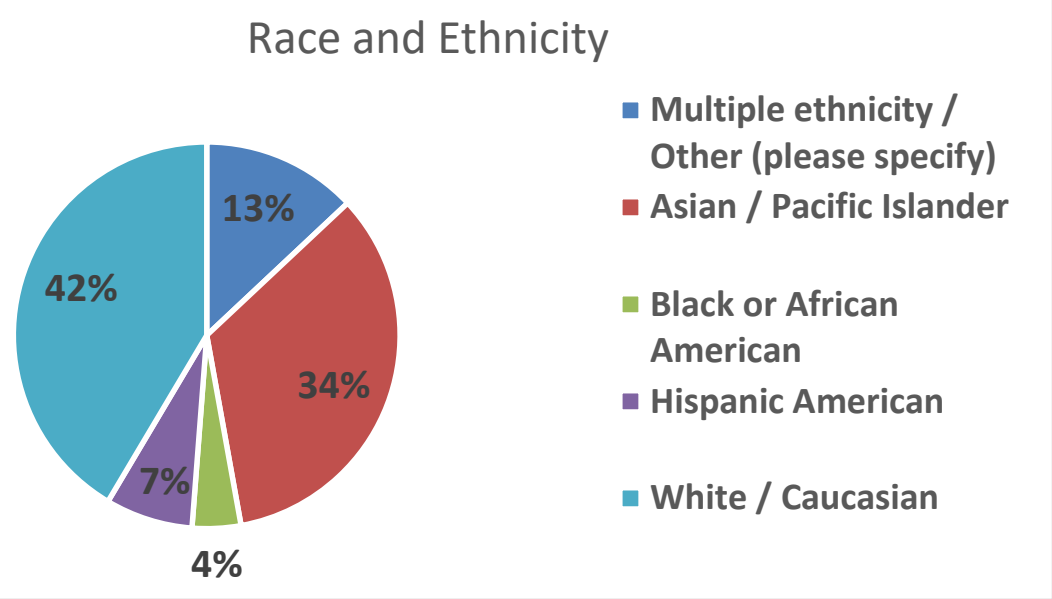

The inclusion criteria for the first phase of the data collection included all undergraduate female students currently enrolled in the college of engineering. In addition to being enrolled full-time 
in engineering, the participants were 18 years of age or older. The participants were on average 20 years of age. The participant pool represented 11 different majors within the college of engineering. The participants' identity and consent were maintained according to IRB requirements and no compensation was offered for completing the survey. The percentages of participant demographics are shown in Figures 1 and 2 which are summarized in Table 2 along with frequency count (Appendix).

Table 2: Self-Reported $1^{\text {st }}$ Generation Status

\begin{tabular}{|c|c|c|c|}
\hline & Frequency & Percent & $\begin{array}{c}\text { Cumulative } \\
\text { Percent }\end{array}$ \\
\hline Yes & 35 & 13.9 & 13.9 \\
\hline No & 216 & 86.1 & 100.0 \\
\hline Total & 251 & 100.0 & \\
\hline
\end{tabular}

Figure 2: Self-Selected Socioeconomic Status (SES) Percentages

\section{Socioeconomic Status}

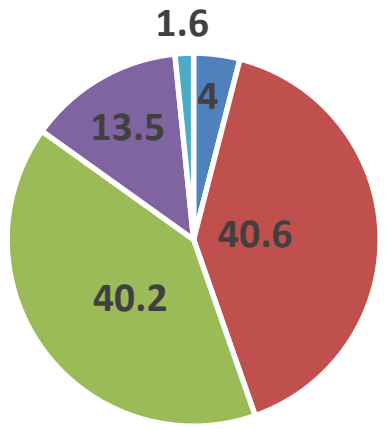

Upper class

- Upper middle class

- Middle class

- Lower middle class

- Below middle class

Table 3: Demographics Summary

\begin{tabular}{||l|c|l|l|c|}
\hline Race/Ethnicity & Frequency & & \multicolumn{1}{|c|}{ SES } & Frequency \\
\hline $\begin{array}{l}\text { Multiple ethnicity / Other } \\
\text { (please specify) }\end{array}$ & $\begin{array}{c}32 \\
(13 \%)\end{array}$ & & Upper class & $\begin{array}{c}10 \\
(4 \%)\end{array}$ \\
\hline Asian / Pacific Islander & $\begin{array}{c}84 \\
(34 \%)\end{array}$ & & Upper middle class & $\begin{array}{c}102 \\
(41 \%)\end{array}$ \\
\hline Black or African American & $\begin{array}{c}10 \\
(4 \%)\end{array}$ & & Middle class & $\begin{array}{c}101 \\
(40 \%)\end{array}$ \\
\hline Hispanic American & 18 & Lower middle class & 34 \\
& $(7 \%)$ & & & $\begin{array}{c}313 \%) \\
(2 \%)\end{array}$ \\
\hline White / Caucasian & 102 & Below middle class & 251 \\
\hline Total & $(42 \%)$ & & & \\
\hline
\end{tabular}




\section{Data Collection}

In the first phase of the study, data collection consisted of a quantitative survey data that was managed through Survey Monkey, which is an online secured data management system. Students accessed the online survey instrument with the link provided in the recruitment email. The survey instrument used established methods including required consenting methods ${ }^{18}$ and provided participation criteria. The survey instrument included the aforementioned published and previously validated measurement scales. The measurement scales included the following: 1) identification with engineering ${ }^{17}$ to measure engineering identity; 2) ethnic identity scale ${ }^{19}$ to measure the level of identification with racial or ethnic identity; 3) Womanist Identity Attitude scale (WIAS) ${ }^{20}$ to measure attitudes reflective of the four stages of womanist identity development (i.e., Pre-encounter, Encounter, Immersion-Emersion, Internalization); the Racial Microaggressions Scale (RMAS) ${ }^{21}$ to measure students perceptions of racial microaggressions; and 4) the Patients Health Questionnaire ${ }^{22}$ is a self-report measure of symptoms of depression. Each scale include Likert type questions with items rated on a 5-point scale that ranges from strongly disagree (1) to strongly agree (5). Sample items from the WIAS include: "I would have accomplished more in this life if I had been born a man" and "I am comfortable wherever I am". The survey instrument concluded with a two open-ended responses to indicate the participant's willingness to be interviewed and demographic information. Demographics included age, gender, gender identity, major, race, SES, and $1^{\text {st }}$ generation status. The participants were asked to provide an email address if they would consider an individual interview as part of the primary data collection for the second phase of the study. The survey completion time typically lasted between 20-35 minutes and the research team will report summative data to maintain anonymity of the participants and only use identifying information to solicit further participation in the research study.

Reliability and validity are important to establish an instrument to accurately characterize complex relationships such as intersecting identities. We compared our Cronbach alpha values to published studies in our previous work ${ }^{23}$. Although, the data as analyzed is insightful, the low Cronbach's alpha for the original 50-item scale suggested a need to employ additional statistical analysis to evaluate the reliability of the subscales for our participant population. We used Hayes' ALPHAMAX procedure ${ }^{24}$ to determine whether a smaller subset of items could be identified that show high internal consistency with this sample. A subset of 22 items (Section 1, questions 1, 5, 7, 9, 12 - 14; Section 3, questions 2, 10, and 14; and Section 3, questions 3, 4, 7, $13-16,18-20$, and $23-25$ ) showed good reliability, suggesting a unidimensional factor structure.

\section{Data Analysis}

Data analysis consisted of classic statistical testing including 1) the internal consistency to measure data reliability and compare with published results; 2) Pearson correlations among constructs to measure the strength of relationship between the various subscales; and 3) analysis of variance to determine if there is a (statistically) significant difference among the population means. The statistics were calculated using the SPSS statistical software. The general descriptive statistics for each subscale were also calculated for the data set. We used Latent Class Analysis 
(the Structural Equation Modeling equivalent of cluster analysis) to identify latent classes with distinct combinations of scores on engineering, ethnic, and womanist identity, microaggressions, and PHQ-9 depression. Because LCA - like cluster analysis - is sensitive to outliers, we screened for values $>2$ SD above the mean on each variable. This resulted in excluding 4 participants were scored very low on engineering identity and also happened to be missing data on all other variables. All variables were z-scored and were then entered into the LCA; using Mplus software, we were able to include all participants, regardless of missing data (via Full Information Maximum Likelihood estimation). A 1-class solution did not converge, and 2-class, 3-class, and 4-class solutions showed progressively better fit (see Table 4; a smaller Bayesian Information Criterion (BIC) and a larger entropy indicate better fit). Based on these fit statistics as well as the size of the latent classes and their interpretability, we selected the 4-class solution as the best solution.

Table 4: Latent Class Characteristics Summary

\begin{tabular}{|c|c|c|}
\hline $\begin{array}{c}\text { Number of Latent } \\
\text { Classes }\end{array}$ & BIC & Entropy (0-1.00) \\
\hline 1 & 8360.090 & N/A \\
\hline 2 & 8352.789 & 0.472 \\
\hline 3 & 8368.822 & 0.507 \\
\hline 4 & 8288.711 & 0.719 \\
\hline
\end{tabular}

\section{Results}

The descriptive statistics including minimum, maximum, mean, standard deviation, and Kurtosis (i.e. a measure of distribution normality) for each scale and sub-scale are displayed below in Table 5.

Table 5: Descriptive Statistics Summary of the Women in Engineering Scales and Sub-scales

\begin{tabular}{|c|c|c|c|c|c|c|c|c|c|}
\hline & $\mathrm{N}$ & Minimum & Maximum & Mean & $\begin{array}{c}\text { Std. } \\
\text { Deviation }\end{array}$ & \multicolumn{2}{|c|}{ Skewness } & \multicolumn{2}{|c|}{ Kurtosis } \\
\hline & Statistic & Statistic & Statistic & Statistic & Statistic & Statistic & $\begin{array}{l}\text { Std. } \\
\text { Error }\end{array}$ & Statistic & $\begin{array}{l}\text { Std. } \\
\text { Error }\end{array}$ \\
\hline ENG_IDTY & 276 & 1.80 & 5.00 & 4.4990 & .42992 & -1.275 & .147 & 4.808 & .292 \\
\hline EI_Exp & 275 & 1.00 & 5.00 & 3.7891 & 1.12191 & -.826 & .147 & -.441 & .293 \\
\hline EI_Com & 275 & 1.00 & 5.00 & 3.9745 & .99214 & -1.073 & .147 & .251 & .293 \\
\hline WIAS_Pre & 276 & 1.13 & 4.00 & 2.0611 & .43594 & .569 & .147 & 1.136 & .292 \\
\hline WIAS_Enc & 275 & 1.57 & 4.29 & 3.0067 & .48212 & -.187 & .147 & .173 & .293 \\
\hline WIAS_ImEm & 276 & 1.00 & 4.00 & 2.5533 & .56124 & -.088 & .147 & .060 & .292 \\
\hline WIAS_Int & 276 & 2.00 & 5.00 & 4.1598 & .38440 & -.772 & .147 & 3.159 & .292 \\
\hline
\end{tabular}




\begin{tabular}{|l|r|r|r|r|r|r|r|r|r|}
\hline RMA_Sem & 254 & 2.00 & 43.00 & $\mathbf{2 2 . 8 4 2 5}$ & 8.39718 & .139 & .153 & -.514 & .304 \\
\hline PHQ_2WK & 254 & .00 & 36.00 & $\mathbf{1 6 . 4 5 2 8}$ & 8.70576 & .179 & .153 & -.760 & .304 \\
\hline
\end{tabular}

The mean of engineering identity shows high levels of identification with engineering which is consistent with previous research ${ }^{17}$. Also, more than $95 \%$ of sample reported high levels of identification with engineering which resulted in a skewed distribution of responses and a leptokurtic or peaked distribution as indicated by the high Kurtosis statistic $(K=4.930>0)$. Also, generally the participants reported high levels racial or ethnic identity (Avg. $=3.8 / 5$ ), but African-Americans and Asians reported higher levels than other racial groups. The elevated scores on the PHQ-9 (Average > 15) corresponds with a "major depression, moderately severe" provisional diagnosis, the second-highest in severity in the PHQ-9 provisional diagnosis scale. Alarmingly, more than $\mathbf{7 0 \%}$ of female student sample $(\mathbf{N}=\mathbf{2 7 6})$ self-reported moderate to severe levels of depression and anxiety (e.g. >10). Based on this result we are providing participants with information on campus resources for mental health support. As we take an intersectional approach in the study, we were also interested in the social dimensions of identity that intersect for our participants. In the Appendix is a table of cross tabulations breakdown of participant demographics by race*SES and race* $1^{\text {st }}$ generation status are displayed below in Tables 8 . The correlations for all the sub-scales are listed in the simple correlation table (Table 6).

Table 6: Simple Correlations of Subscales

\begin{tabular}{|c|c|c|c|c|c|c|c|c|c|}
\hline & $\begin{array}{l}\text { ENG }_{-} \\
\text {IDTY1 }\end{array}$ & $\begin{array}{l}\text { EI } \\
\text { EXP }\end{array}$ & $\begin{array}{c}\mathrm{EI} \\
\mathrm{COM}\end{array}$ & $\begin{array}{c}\text { WIAS } \\
\text { PRE }\end{array}$ & $\begin{array}{c}\text { WIAS } \\
\text { ENC } \\
\end{array}$ & $\begin{array}{l}\text { WIAS } \\
\text { IMEM }\end{array}$ & $\begin{array}{c}\text { WIAS } \\
\text { INT }\end{array}$ & $\begin{array}{c}\text { RMA }_{-} \\
\text {SEM }\end{array}$ & $\begin{array}{c}\text { PHQ_ } \\
\text { WK }\end{array}$ \\
\hline $\begin{array}{l}\text { ENG }_{\overline{-}} \\
\text { IDTY }^{2}\end{array}$ & 1 & & & & & & & & \\
\hline EI_EXP & 0.051 & 1 & & & & & & & \\
\hline EI_COM & 0.037 &. $\mathbf{5 8 9}^{* * *}$ & 1 & & & & & & \\
\hline $\begin{array}{c}\text { WIAS_ } \\
\text { PRE }\end{array}$ & -0.005 & $-.170^{* * *}$ & $-.166^{* *}$ & 1 & & & & & \\
\hline $\begin{array}{c}\text { WIAS_ } \\
\text { ENC }\end{array}$ & -0.043 & $.189^{* * *}$ & 0.078 & 0.098 & 1 & & & & \\
\hline $\begin{array}{l}\text { WIAS } \\
\text { IMEM }\end{array}$ & 0.013 & 0.110 & 0.010 & $.131^{*}$ & $.613^{* *}$ & 1 & & & \\
\hline $\begin{array}{c}\text { WIAS }_{-} \\
\text {INT }\end{array}$ & $.142^{*}$ & 0.034 & -0.010 & $-.240^{* *}$ & -0.055 & $-.234^{* *}$ & 1 & & \\
\hline $\begin{array}{c}\text { RMA }_{-} \\
\text {SEM }\end{array}$ & 0.019 & $.164^{* * *}$ & $.142^{*}$ & 0.050 & $.130^{*}$ & $.232^{* *}$ & 0.036 & 1 & \\
\hline $\begin{array}{c}\text { PHQ } \\
\text { WK }\end{array}$ & -0.094 & -0.050 & 0.021 & 0.046 & $.189^{* *}$ & $.350^{* *}$ & $-.169^{* *}$ & $.220^{* *}$ & 1 \\
\hline
\end{tabular}

*. Correlation is significant at the 0.05 level. **. Correlation is significant at the 0.01 level.

The statistically significant relationships are bolded. The only significant difference between racial groups observed by cross tabulation were the reported frequency of perceptions of racial microaggressions. We concluded that the self-reported RMA varied by race based on the analysis 
results displayed in Table 10 in the appendix. The Chi-Test value $=212.621>$ critical value (9.49), therefore we REJECT $\mathrm{H}_{0}$. We reject the null hypothesis that reported levels RMA are the same for all races. The self-reported frequency of racial microaggressions significantly differ by race, $X 2(4, \mathrm{~N}=246)=0.000, p>.05$ and we accept the $\mathrm{H}_{1}$ hypothesis as true that 'the reported levels of RMA are different for women of color and other females' studying engineering. Also, were calculated the correlations for all the scales and sub-scales. Interestingly, the elevated PHQ scores were correlated with microaggressions $[\mathrm{r}(243)=.22, \mathrm{p}<.01]$. This relationship will be further explored in the individual interviews.

Based on the correlations, engineering identity was related to the internalization sub-scale of the WIAS. The internalization level is an indication that a women has integrated a personally defined positive view of womanhood into their identity despite cultural norms or the antithetical positions of the women ${ }^{20}$. The results suggest that the participants were able to integrate a positive womanist identity into their engineering identity. Also, the exploration subscale of ethnic identity measure correlated with multiple scales (4: commitment subscale of ethnic identity, pre-encounter and encounter phases of the WIAS, and the racial microaggressions measure). The racial ethnic subscale of exploration is defined as seeking information and experiences relevant to one's ethnicity (e.g. learning cultural practices), but it supports the commitment to one's ethnic racial identity and critical to the process of ethnic identity formation 19. The combinations of the multiple correlated identity scales suggest the presence of intersecting identities of the participants, but more importantly the variations in the intersecting identities, which is consistent with previous research ${ }^{25}$. That is to say, the intersection of race and gender or gender and engineering identities varies between and within racial groups.

Other evidence that suggests the differences between and among racial groups is found in our Analysis of Variance (ANOVA) calculations. We created One-way ANOVA tables to identify which social classification (e.g. major, race, SES, or $1^{\text {st }} \mathrm{Gen}$ ) varied between WOC and other females for each sub-scale. A one way analysis of variance showed that the effect of commitment subscales of ethnic identity was significant, $F(4,241)=3.129, p=.016$. Comparing the Fstatistics to the critical value 2.37 indicates significant differences in racial microaggressions, both ethnic identity subscales, and the immersion-emersion subscale of the WIAS. Table 7 summarizes the ANOVA calculations for each subscale. The overall trend was for higher ethnic identity among African-American and Asian students, and higher engineering identity among White students. White students showed low levels of microaggressions and depression, whereas students in other groups had more mixed patterns. Some Black and Hispanic students self-reported high levels of microaggressions and depression, whereas others reported low levels of both. Asian students showed the same patterns, but not in general low on engineering identity.

Table 7: ANOVA by Race $($ Fcrit $=2.37, \mathrm{p}<.05)$

\begin{tabular}{|l|c|c|l|l|l|}
\hline $\begin{array}{l}\text { ANOVA } \\
\text { Summary }\end{array}$ & $\begin{array}{l}\text { Sum of } \\
\text { Squares }\end{array}$ & df & $\begin{array}{l}\text { Mean } \\
\text { Square }\end{array}$ & F & Sig. \\
\hline ENG_IDTY & 0.823 & 241 & 0.189 & 1.089 & 0.363 \\
\hline
\end{tabular}




\begin{tabular}{|l|c|c|c|c|c|}
\hline EI_EXP & 268.664 & 241 & 1.115 & $\mathbf{6 . 7 2 5}$ & 0.000 \\
\hline EI_COM & 235.107 & 241 & 0.976 & $\mathbf{3 . 1 2 9}$ & 0.016 \\
\hline WIAS_PRE & 41.963 & 241 & 0.174 & 1.513 & 0.199 \\
\hline WIAS_ENC & 55.610 & 241 & 0.231 & 1.328 & 0.260 \\
\hline WIAS_IMEM & 72.055 & 241 & 0.299 & $\mathbf{2 . 8 6 6}$ & 0.024 \\
\hline WIAS_INT & 32.279 & 241 & 0.133 & 0.437 & 0.782 \\
\hline RMA_2SEM & 13021.911 & 241 & 54.033 & $\mathbf{1 7 . 0 4 1}$ & 0.000 \\
\hline PHQ_2WK & 18386.470 & 241 & 76.292 & 0.781 & 0.538 \\
& & & & & \\
\hline
\end{tabular}

\section{Discussion}

Understanding the intersection of identities for women studying engineering is an important topic to understand as we strive to broaden their participation. In this paper, we highlight our process to develop a valid and reliable process to characterize the experiences of women in engineering and how those experiences can impact their multiple identities, including developing an engineering identity. In answering our first research question, all the subscale generated similar reliability values as other studies, but we identified a subset of items within the WIAS subscales that significantly increased the accuracy of the response scores. The answer to our second research question is the results of a combination of multiple statistics. Through multiple calculations, our results indicate significant relationships between the construct within the Women in Engineering survey instruments and also suggest intersecting identities of female participants in the study. For example, engineering identity was correlated to the internalization sub-scale of the WIAS. This result is important to demonstrate examples of an integrated and coherent (e.g. non-conflicting) gender and professional identity formation is possible for female students in engineering. Also, the racial/ethnic identity correlated to several construct, which suggest race still impacts female students' identity development and experiences in engineering. Furthermore, ethnic identity is key to the current study as the ANOVA results identified variation between races experiencing racial microaggressions. Finally, higher levels of experiencing RMA's also correlated to higher self-reported levels of depressive symptoms. This finding is consistent with previous work on RMA, in the broader context of higher education, but we are excited to initiate the conversation about mental health in the context of engineering education.

\section{Conclusion}

In conclusion, we report a few key findings. First, we identified a basis to modify the original survey to a more accurate measurement of womanist identity. Next, the females in our study generally have a strong engineering identity and a significant portion of those female reported elevated levels of anxiety and depression. The elevated levels of depressive symptoms correlated 
to more racial microaggressions. Which leads to our last finding, that we found evidence of intersecting identities among the participants and variation of intersections within each racial group. Therefore, understanding why the variation emerged within racial groups is a next step in our project.

Additional future work and the limitations of our study should be considered in reflecting on the results of our study. One limitation that is related to future work is the collection of quantitative survey responses only in the current analysis. We are currently conducting in-depth interviews to discuss survey responses with participants. The interviews will help us understand how the intersecting identities of race and gender can impact the education of women in engineering, especially WOC. Also, the interview will allow participants to describe the intersection of their identities, as explicit intersecting identity items were not included in the survey. Another limitation of our study is the data collected is from a single research intensive university. In our future work we also plan to collaborate with other institutions to administer the survey instrument to compare results across institutions. Despite these limitations, the results our current study is initiating dialogue about the importance of targeted approaches to developing positive identity development process for women in engineering, especially WOC.

\section{References}

1 Crawford, M. \& MacLeod, M. Gender in the college classroom: An assessment of the "chilly climate" for women. Sex Roles 23, 101-122 (1990).

2 Whitt, E. J., Edison, M. I., Pascarella, E. T., Nora, A. \& Terenzini, P. T. Women's perceptions of a" chilly climate" and cognitive outcomes in college: Additional evidence. Journal of College Student Development (1999).

3 Walton, G. M., Logel, C., Peach, J. M., Spencer, S. J. \& Zanna, M. P. Two brief interventions to mitigate a "chilly climate" transform women's experience, relationships, and achievement in engineering. Journal of Educational Psychology 107, 468 (2015).

4 Foor, C. E., Walden, S. E. \& Trytten, D. A. "I Wish that I Belonged More in this Whole Engineering Group:" Achieving Individual Diversity. Journal of Engineering Education 96, 103-115 (2007).

5 Cross, K. J. The Experiences of African-American Males on Multiracial Student Teams in Engineering PhD thesis, Virginia Tech, (2015).

6 Gusa, D. L. White institutional presence: The impact of Whiteness on campus climate. Harvard Educational Review 80, 464-490 (2010).

7 Walton, G. M. \& Cohen, G. L. A brief social-belonging intervention improves academic and health outcomes of minority students. Science 331, 1447-1451 (2011).

8 Logel, C. et al. Interacting with sexist men triggers social identity threat among female engineers. Journal of personality and social psychology 96, 1089 (2009).

9 Jones, S. R. Intersectionality in educational research. (Stylus Publishing, LLC, 2015).

10 Creswell, J. W. \& Clark, V. L. P. Designing and conducting mixed methods research. (2007).

11 Hankivsky, O. \& Grace, D. in The Oxford handbook of multimethod and mixed methods research inquiry (2015). 
12 Griffin, K. A. \& Museus, S. D. Using mixed methods to study intersectionality in higher education: New directions in institutional research, number 151. Vol. 113 (John Wiley \& Sons, 2011).

13 Settles, I. H. Use of an intersectional framework to understand Black women's racial and gender identities. Sex Roles 54, 589-601 (2006).

14 Ro, H. K. \& Loya, K. I. The effect of gender and race intersectionality on student learning outcomes in engineering. The Review of Higher Education 38, 359-396 (2015).

15 O'Brien, L. T., Blodorn, A., Adams, G., Garcia, D. M. \& Hammer, E. Ethnic variation in gender-STEM stereotypes and STEM participation: An intersectional approach. Cultural Diversity and Ethnic Minority Psychology 21, 169-180, doi:10.1037/a0037944 (2015).

16 Jones, S. R., Olive, J. L., Davis, D. J. \& Brunn-Bevel, R. J. Intersectionality in Educational Research. (Stylus Publishing, LLC, 2015).

17 Jones, B. D., Paretti, M. C., Hein, S. F. \& Knott, T. W. An Analysis of Motivation Constructs with First-Year Engineering Students: Relationships Among Expectancies, Values, Achievement, and Career Plans. Journal of Engineering Education 99, 319-336 (2010).

18 Creswell, J. W. Research Design: Qualitative \& Quantitative Approaches. 4th edn, (Sage Publications, Inc, 2017).

19 Phinney, J. S. \& Ong, A. D. Conceptualization and measurement of ethnic identity: Current status and future directions. Journal of Counseling Psychology 54, 271-281, doi:10.1037/0022-0167.54.3.271 (2007).

20 Moradi, B., Yoder, J. D. \& Berendsen, L. L. An evaluation of the psychometric properties of the Womanist Identity Attitudes Scale. Sex Roles 50, 253-266 (2004).

21 Torres-Harding, S. R., Andrade Jr, A. L. \& Romero Diaz, C. E. The Racial Microaggressions Scale (RMAS): a new scale to measure experiences of racial microaggressions in people of color. Cultural Diversity and Ethnic Minority Psychology 18, 153 (2012).

22 Kroenke, K., Spitzer, R. L. \& Williams, J. B. The Phq-9. Journal of general internal medicine 16, 606-613 (2001).

23 Cross, K. J., Mendenhal, R., Clancy, K. \& Amos, J. in Proceedings-American Society of Engineering Education Annual Conference \& Exposition (ASEE), Columbus, OH. June 24-28, 2017.

24 Hayes, A. in meeting of the Midwestern Association for Public Opinion Research, Chicago, IL.

25 Ong, M., Wright, C., Espinosa, L. L. \& Orfield, G. Inside the Double Bind: A Synthesis of Empirical Research on Undergraduate and Graduate Women of Color in Science, Technology, Engineering,and Mathematics. Harvard Educational Review 81, 172-209 (2011).

\section{Appendix}

Additional Tables of Statistical Calculations to Support Conclusions

Table 8: Cross Tabulation Economic Group (SES) and 1st Generation by Race 


\begin{tabular}{|c|c|c|c|c|c|c|}
\hline $\begin{array}{l}\text { Socioeconomic } \\
\text { Status }\end{array}$ & $\begin{array}{l}\text { Multiple } \\
\text { ethnicity }\end{array}$ & $\begin{array}{l}\text { Asian / } \\
\text { Pacific } \\
\text { Islander } \\
\end{array}$ & $\begin{array}{c}\text { Black or } \\
\text { African } \\
\text { American }\end{array}$ & $\begin{array}{l}\text { Hispanic } \\
\text { American }\end{array}$ & $\begin{array}{c}\text { White / } \\
\text { Caucasian }\end{array}$ & \\
\hline Upper class & 1 & 3 & 0 & 3 & 2 & 9 \\
\hline $\begin{array}{l}\text { Upper middle } \\
\text { class }\end{array}$ & 13 & 39 & 1 & 2 & 47 & 102 \\
\hline Middle class & 14 & 36 & 5 & 4 & 38 & 97 \\
\hline $\begin{array}{l}\text { Lower middle } \\
\text { class }\end{array}$ & 4 & 5 & 4 & 7 & 14 & 34 \\
\hline $\begin{array}{l}\text { Below middle } \\
\text { class }\end{array}$ & 0 & 1 & 0 & 2 & 1 & 4 \\
\hline Total & 32 & 84 & 10 & 18 & 102 & 246 \\
\hline $\begin{array}{l}1^{\text {st }} \text { Generation } \\
\text { Status }\end{array}$ & $\begin{array}{l}\text { Multiple } \\
\text { ethnicity }\end{array}$ & $\begin{array}{l}\text { Asian / } \\
\text { Pacific } \\
\text { Islander }\end{array}$ & $\begin{array}{l}\text { Black or } \\
\text { African } \\
\text { American }\end{array}$ & $\begin{array}{l}\text { Hispanic } \\
\text { American }\end{array}$ & $\begin{array}{c}\text { White / } \\
\text { Caucasian }\end{array}$ & \\
\hline Yes & 1 & 10 & 2 & 10 & 12 & 35 \\
\hline No & 31 & 74 & 8 & 8 & 90 & 211 \\
\hline Total & 32 & 84 & 10 & 18 & 102 & 246 \\
\hline
\end{tabular}

Table 9: Cross Tabulations of Race*RMA (racial microaggressions scores)

\begin{tabular}{|c|c|c|c|c|c|c|c|}
\hline & & $\begin{array}{c}\text { Multiple } \\
\text { ethnicity / } \\
\text { Other (please } \\
\text { specify) }\end{array}$ & $\begin{array}{c}\text { Asian / Pacific } \\
\text { Islander }\end{array}$ & $\begin{array}{l}\text { Black or } \\
\text { African } \\
\text { American }\end{array}$ & $\begin{array}{l}\text { Hispanic } \\
\text { American }\end{array}$ & $\begin{array}{c}\text { White / } \\
\text { Caucasian }\end{array}$ & Total \\
\hline \multirow[t]{14}{*}{ RMA_Sem } & 9.00 & 2 & 0 & 0 & 0 & 9 & 11 \\
\hline & 10.00 & 0 & 0 & 0 & 0 & 4 & 4 \\
\hline & 11.00 & 1 & 1 & 0 & 0 & 5 & 7 \\
\hline & 12.00 & 1 & 1 & 0 & 1 & 4 & 7 \\
\hline & 13.00 & 0 & 2 & 0 & 0 & 9 & 11 \\
\hline & 14.00 & 3 & 1 & 0 & 0 & 2 & 6 \\
\hline & 15.00 & 0 & 3 & 1 & 1 & 3 & 8 \\
\hline & 16.00 & 1 & 2 & 0 & 0 & 5 & 8 \\
\hline & 17.00 & 2 & 1 & 0 & 0 & 6 & 9 \\
\hline & 18.00 & 0 & 2 & 1 & 0 & 6 & 9 \\
\hline & 19.00 & 1 & 6 & 0 & 1 & 0 & 8 \\
\hline & 20.00 & 0 & 4 & 0 & 0 & 4 & 8 \\
\hline & 21.00 & 0 & 4 & 0 & 1 & 7 & 12 \\
\hline & 22.00 & 2 & 6 & 0 & 0 & 4 & 12 \\
\hline
\end{tabular}




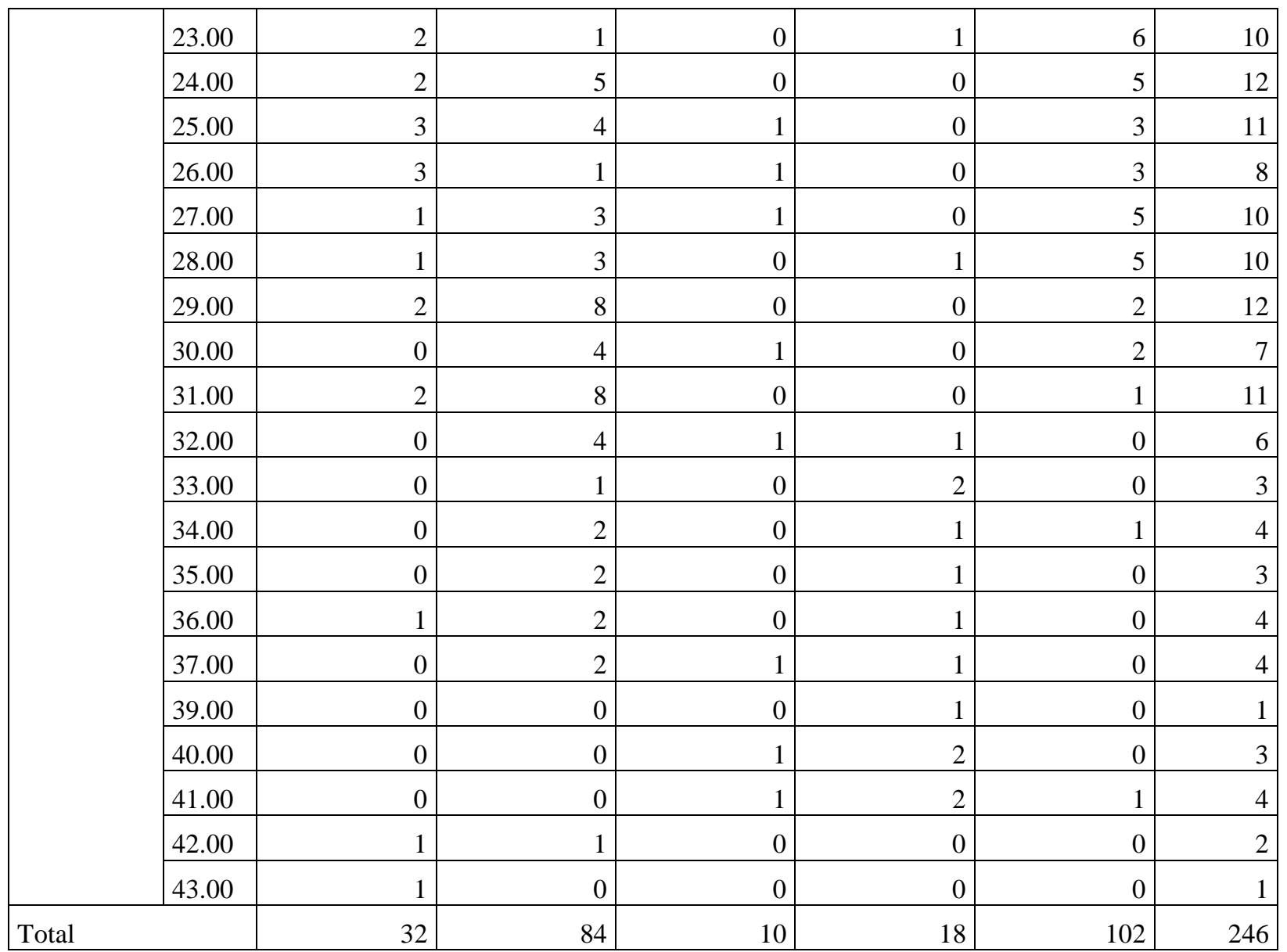

Table 10: Chi-Square Tests (Crosstab Race*RMA)

\begin{tabular}{|l|r|r|r|}
\hline & \multicolumn{1}{|c|}{ Value } & \multicolumn{1}{c|}{ df } & \multicolumn{1}{c|}{$\begin{array}{c}\text { Asymptotic } \\
\text { Significance } \\
\text { (2-sided) }\end{array}$} \\
\hline Pearson Chi-Square & \multicolumn{1}{|c|}{$212.621^{\mathrm{a}}$} & 132 & .000 \\
\hline Likelihood Ratio & 204.480 & 132 & .000 \\
\hline $\begin{array}{l}\text { Linear-by-Linear } \\
\text { Association }\end{array}$ & 14.600 & 1 & .000 \\
\hline N of Valid Cases & 246 & & \\
\hline
\end{tabular}

a. 170 cells $(100.0 \%)$ have expected count less than 5 . The minimum expected count is .04 . 